\title{
O LUGAR DA LITERATURA NO ENSINO DE ESPANHOL COMO LÍNGUA ESTRANGEIRA
}

\author{
Camila Dantas Muniz
}

IFRN - Campus Natal Central. E-mail: camilamuniz07@hotmail.com

Ilane Ferreira Cavalcante

Professora do IFRN - Campus Natal Central. E-mail: ilane@cefetrn.br

\section{RESUMO}

Este trabalho deriva de um projeto de pesquisa de iniciação científica apoiado pelo CNPq que se dispõe a examinar o uso de textos literários no ensino de línguas estrangeiras, mais especificamente de língua espanhola, para posteriormente construir um material adequado de conteúdo literário voltado ao ensino do espanhol como língua estrangeira. Em um primeiro momento, se discute a presença do próprio ensino do espanhol no Brasil e o seu desenvolvimento à luz das orientações curriculares nacionais. Em seguida, introduz-se a relação existente entre a literatura e o ensino para a formação completa do aluno, refletindo acerca da utilização da literatura no ensino de línguas estrangeiras e, por fim, apresentamse algumas considerações sobre a inserção de elementos literários nas aulas de espanhol.

PALAVRAS-CHAVE: literatura; língua estrangeira; ensino de espanhol como língua estrangeira; textos literários no ensino de E/LE. 


\section{O LUGAR DA LITERATURA NO ENSINO DE ESPANHOL COMO LÍNGUA ESTRANGEIRA}

\section{INTRODUÇÃO}

O ensino de espanhol como língua estrangeira no Brasil foi regulamentado através da Lei $\mathrm{n}^{0} 11.161$ de 05 de agosto de 2005. Desde então, a formação de professores para atuarem no ensino fundamental e médio têm sido uma prioridade do governo e das instituições de ensino superior do país. Mas há outra preocupação aliada a essa, a da qualidade desse ensino. Essa outra preocupação se ampara na realidade do ensino de língua inglesa, que tem sido prioritário nesses níveis de ensino no Brasil ao longo de sua história. O ensino de língua inglesa tem suscitado inúmeros estudos e inúmeras propostas, mas sua qualidade tem esbarrado, entre outros problemas, na falta de infra-estrutura da rede de ensino (desde salas adequadas até equipamentos necessários), ou na quantidade de estudantes por sala de aula, incompatível para a qualidade de um ensino voltado para a comunicação.

Essas questões que cercam a qualidade do ensino de língua inglesa no país também podem afetar o ensino de espanhol como língua estrangeira (E/LE). Mas o espanhol apresenta algumas possibilidades de vantagem: é uma língua mais próxima do português, por ser de origem latina e também em termos geográficos, por estarmos em um país cercado de países falantes do espanhol. Por outro lado, é também uma língua a que muitos brasileiros consideram menos importante, em termos de mercado de trabalho, ou mais fácil, concluindo ser desnecessário o seu aprendizado formal.

Somado a tudo isso, por ser a lei de ensino de E/LE muito recente, ainda há uma grande lacuna de bons materiais de ensino e, principalmente, de materiais adequados à realidade nacional.

O projeto de pesquisa de que esse artigo é fruto se propõe a refletir sobre o ensino de E/LE no Brasil, analisando a proposta oficial através dos Parâmetros Curriculares Nacionais e pensando na inclusão da leitura como uma etapa importante desse processo. Dessa forma, o objetivo deste projeto é pesquisar textos e elaborar atividades que correspondam aos parâmetros teóricos e metodológicos dinâmicos e estimulantes para aplicação em salas de aula de língua espanhola em turmas de Ensino Médio. Trabalhando conteúdos que possam proporcionar, através do uso da língua, a compreensão e a reflexão sobre a própria identidade, sobre a importância de uma língua estrangeira para a formação profissional e sobre a capacidade de construção do conhecimento.

O projeto prevê, portanto, a pesquisa e seleção de material autêntico constituindo uma espécie de banco de dados e, posteriormente, um livro didático voltado para professores de Ensino Médio Regular, adequado a essa modalidade e a esse público. Esse trabalho constitui-se um desafio pedagógico que as instituições formadoras precisam vencer visando um aprofundamento teórico e metodológico que venha a contribuir para a melhoria do processo de ensino e, conseqüentemente, da aprendizagem do estudante.

O objetivo proposto, a produção desse banco de atividades, serviria como uma base, um suporte de pesquisa que facilitaria o trabalho dos professores de Espanhol como Língua Estrangeira do Ensino Médio. Na verdade, procura-se fornecer subsídios práticos e estratégias interessantes de utilização da literatura no ensino de língua estrangeira. 


\section{O ENSINO DO ESPANHOL NO BRASIL}

A língua espanhola figura entre as dez mais faladas no mundo e assume o posto de primeiro lugar nas Américas, crescendo mais e mais o número de hispanofalantes. A globalização, as estreitas relações com os países vizinhos, que tem o espanhol como língua oficial, e a participação do país no Mercado Comum do Sul (Mercosul), por conseguinte, são fatores que contribuem e estimulam atualmente o crescente interesse por seu estudo no país.

Por anos, a inclusão do espanhol como língua estrangeira nos currículos escolares brasileiros foi tema secundário, de pouco relevo. Contudo, a partir da promulgação da Lei $\mathrm{n}^{\circ} 11.161 / 2005$, que dispõe sobre o ensino da língua espanhola, torna-se obrigatória a sua oferta nas escolas públicas e privadas de ensino médio e facultativa nos currículos plenos do $6^{\circ}$ ao $9^{\circ}$ ano do ensino fundamental. É imprescindível, então, nessa presença do espanhol no Brasil, pensar-se em seu processo de ensino-aprendizagem, haja vista que, apesar de guardar semelhanças com a língua nacional e ser, aparentemente, de fácil compreensão para os lusófonos brasileiros, o espanhol traz suas diferenças lingüísticas à socapa; fazendo-se necessário, portanto, um estudo mais cuidadoso para o desenvolvimento de sua fluência e para a desmistificação da idéia de que sua aprendizagem, por ser considerada uma "língua fácil", dispensaria a necessidade de um estudo formal. A variedade dos heterossemânticos - falsos cognatos -, por exemplo, demonstra a devida atenção requerida pelo ensino-aprendizagem dessa língua.

Tendo em consideração o exposto acima, as orientações curriculares nacionais para o ensino da língua espanhola no Ensino Médio destacam a necessidade de se abordar não apenas os conteúdos gramaticais e lexicais, mas também de se explorar a heterogeneidade lingüística do seu objeto de estudo em seus aspectos contextual, social, cultural e histórico, com o intuito de que se forme no aluno uma consciência crítica da existência dessa heterogeneidade e diversidade lingüística e sociocultural.

Entre as considerações apresentadas no documento síntese do II Encontro Nacional sobre Política de Ensino de Línguas Estrangeiras, realizado em Pelotas/RS, está que o ensino de línguas estrangeiras deve libertar-se da dinâmica mecanicista normalmente empregada em seu ensino-aprendizagem e incentivar a formação integral do aluno, direcionada, como apontam as orientações curriculares nacionais para o ensino médio, aos valores de cidadania e de completude do ser humano.

Junger (2005) aponta que tanto a Lei de Diretrizes e Bases da Educação Nacional quanto os Parâmetros Curriculares Nacionais traçam, implícita ou explicitamente, como objetivo do processo educativo, entre outros, o auto-conhecimento decorrente do contato com o outro, o desfazimento de preconceitos, o desenvolvimento do potencial para a convivência e o respeito intercultural, o incentivo à construção do pensamento crítico.

A proposta é despertar no aluno uma percepção de linguagem que ultrapasse seu caráter instrumental de meio de expressão e comunicação para que busque mais além e alcance o entendimento de que a linguagem se constitui de significados, conhecimentos e valores, de modo que o ensino do espanhol como língua estrangeira colabore com as demais disciplinas para a construção coletiva do conhecimento e para a formação cidadã. Em termos gerais, tem-se que: 
[...] a língua estrangeira não é simplesmente matéria escolar a ser aprendida, mas tem função educacional, e um dos seus papéis mais importantes, o de expor os alunos a outra língua a partir de uma óptica menos instrumental, poderá ajudar, entre outras coisas, a interferir positivamente na relação que os estudantes brasileiros guardam com a própria língua, em especial com a escrita. (BRASIL, 2006, p. 133)

A literatura serve, pois, de estímulo ao desenvolvimento do aluno como ser humano e como cidadão, ao dar-lhe novas dimensões e ao possibilitar-lhe uma percepção holística do mundo.

\section{A LITERATURA NO CONTEXTO DE UMA LÍNGUA ESTRANGEIRA}

Desde o último século, a funcionalidade dos textos literários no contexto do ensinoaprendizagem de uma língua estrangeira passou por inúmeras interpretações metodológicas.

O uso extensivo da literatura no modelo gramatical contribuiu para que esse fosse o foco de sua proposta de ensino cujo cerne se encontrava na tradução, memorização das regras gramaticais e imitação das mostras "elevadas" de língua. A adoção de textos literários se centrava no seu uso como fonte de vocabulário e de estruturas gramaticais, exercendo a função de mero instrumento de aprendizagem e fixação do modelo culto da língua a ser aprendida e não deixava margem para as atividades de interpretação e compreensão dos textos.

A abordagem metodológica que o sucedeu tinha por foco a língua oral, cujo objetivo constituía-se em imitar a pronuncia de palavras e frases da maneira mais próxima possível a dos nativos do idioma estudado. O texto ocupava um segundo plano, trabalhado tãosomente após o aproveitamento satisfatório da prática oral em um modelo desenhado e controlado com uma finalidade puramente didática. Compreendia-se, nesse primeiro momento, a literatura como uma representação estática e tortuosa da linguagem, que guardava pouca ou nenhuma relação com a comunicação corriqueira, cotidiana, o que se enfatizava era um modelo mais neutro, mais funcional da língua meta que atendia as necessidades comunicativas práticas para o fim a que se destinava (negócios, compras, viagens, turismo, etc.).

Com a evolução da abordagem comunicativa, há o ressurgimento da leitura dentro do marco da comunicação, mas o seu uso dava-se mais como pretexto para atingir os objetivos comunicativos e focava-se na discussão.

A partir de meados da década de 1990, o uso da literatura retorna pouco a pouco aos materiais e métodos de ensino de línguas estrangeiras.

Martínez Sallés (2004, p. 2) indica, grosso modo, que a didática específica dos materiais literários se baseia majoritariamente em dois aspectos: (a) a sua condição de textos autênticos, ou seja, de mostras culturais da língua que os alunos aprendem e (b) a sua condição de textos lingüisticamente fecundos, de indubitável qualidade, que oferecem um input privilegiado para desenvolver as quatro destrezas lingüísticas fundamentais para a 
aprendizagem de uma língua: compreensão leitora, expressão escrita, compreensão auditiva e expressão oral dentro de um contexto cultural significativo. Seguindo a mesma linha de pensamento, Sanz González agrega que:

Ha de trabajarse siempre sobre textos auténticos, es decir, textos que constituyan parte de la vida de los nativos de la lengua que se estudia. No deben rechazarse textos que a primera vista puedan parecer demasiado difíciles; los resultados pueden demostrar al final que dan mejores frutos que los más fáciles, sobre todo con alumnos acostumbrados a motivarse con retos. La simplificación llegará después, al sustituir algunas estructuras, al redactar de nuevo alguna parte del texto con recursos más llanos, o haciendo un resumen con los medios propios del alumno. Sucede a menudo que lo que resulta verdaderamente difícil no es el texto en sí sino las actividades que sobre el mismo se les impone después. (1995, p. $122)^{1}$

A escolha apropriada do texto por parte do professor e o uso de estratégias e atividades que facilitem a introdução e o entendimento de novas estruturas podem suplantar qualquer dificuldade lingüística inicial enfrentada pelo aluno.

Portanto, o uso de textos literários nas aulas de língua estrangeira proporciona ao professor novas dimensões e caminhos para que o processo de aprendizagem do aluno inclua questões culturais e não apenas gramaticais ou estruturais. Mais ainda, potencializa a formação de um ser humano completo e consciente, na medida em que a literatura colabora com a promoção do auto-conhecimento, da compreensão do comportamento humano e do enriquecimento cultural.

[...] from the teacher's point of view, literature, which speaks to the heart as much as to the mind, provides material with some emotional colour, that can make fuller contact with the learner's own life, and can thus counterbalance the more fragmented effect of many collections of text used in the classroom. (COLLIE; SLATER, 1987, p. 2) ${ }^{2}$

A literatura, ao mesmo tempo que possibilita o diálogo com outras culturas, trata também de temas universais capazes de promover a identificação do leitor por mais distinta que seja a realidade apresentada. A universalidade dos temas literários, por mais distinto que seja a sua forma de abordá-los, mantém o seu apelo humano. (ALBALADEJO, 2007, p. 6)

\footnotetext{
${ }^{1}$ Tem que se trabalhar sempre com textos autênticos, isto é, textos que constituam parte da vida dos nativos da língua que se estuda. Não se devem rejeitar textos que a primeira vista pareçam excessivamente difíceis; os resultados podem demonstrar no final que esses dão melhores resultados que os mais fáceis, sobretudo com alunos acostumados a motivarem-se quando desafiados. A simplificação virá depois ao substituir algumas estruturas, ao redatar de novo alguma parte do texto com recursos mais simples ou fazendo um resumo com as próprias palavras do aluno. Resulta frequentemente que a verdadeira dificuldade não é o texto em si senão as atividades que sobre o mesmo lhes são impostas depois.

2 [...] do ponto de vista do professor, a literatura, que fala ao coração tanto quanto à mente, oferece material com certa nuance emocional que pode aproximar-se mais da própria vida do estudante e pode assim compensar o efeito mais fragmentado de muitas seleções de textos usadas na sala de aula.
} 
O amor, a revolta, o nascimento, a morte, são elementos comuns a todas as culturas e nos unem de um modo ou outro, em diferentes graus de proximidade, com o resto da humanidade, conferindo à obra literária um quê de reconhecimento, de familiaridade com a realidade na qual se encontra inserido o leitor.

Figurative language yokes levels of experience that were previously distinct, casting a new light on familiar sensations and opening up new dimensions of perception in a way that can be exhilarating but also startling and even unsettling. (Ibid., p. 5) ${ }^{3}$

O envolvimento do aluno com o texto lhe permite ir além dos aspectos mecanicistas do ensino-aprendizagem de uma língua estrangeira e promove um verdadeiro mergulho imaginário naquele mundo fictício em que o leitor se sente parte do que lê.

Desse modo, além de permitir ao aluno a sua familiarização com vários aspectos da língua estudada, tais como a formação e a estrutura dos enunciados e as diversas formas possíveis de se transmitir uma idéia - útil no desenvolvimento de suas próprias habilidades escritas , trabalha sua capacidade de premeditar e de inferir o significado do que lhe é desconhecido.

A inserção de textos literários no ensino de línguas estrangeiras beneficia o entendimento e a contemplação pelo aluno de culturas e valores diferentes dos seus. Através da leitura, o aluno imerge na experiência cultural de outros costumes e de outras formas de pensar, familiarizando-se com padrões de interação social distintos.

\section{PENSANDO A LITERATURA NO ENSINO DE E/LE}

A globalização vem exigindo que a escola enfrente desafios cada vez mais abrangentes. Nesse processo, o ensino de língua estrangeira tem enfrentado diversas modificações, fugindo do modelo tradicional que visava apenas a estrutura da língua e apelando não apenas para a comunicação básica, mas para a qualidade da leitura.

No Brasil, somado a esses fatores, agrega-se a nova necessidade de ensino de E/LE, o que implica na formação de professores, na elaboração de material didático adequado à situação nacional e no estímulo ao aprendizado novo processo. É preciso evitar, portanto, uma mera transmissão de conhecimentos voltada apenas para a estrutura básica da língua, sem agregar leitura, cultura, comunicação para melhor situar o papel da escola na organização dos aprendizes dessa nova língua.

Dentro desse cenário, a escola ganha uma dimensão ainda mais relevante na formação de cidadãos críticos e preparados para agir em várias instâncias sociais. Para alcançar esse objetivo, é preciso que ela desenvolva formas de inserir os estudantes em práticas sociais de letramento que incluam não só a língua materna, mas as línguas estrangeiras, de maneira a visar uma formação escolar adequada às novas demandas sociais e profissionais que esses indivíduos terão, ademais de promover o sentimento de inclusão freqüentemente associado ao conhecimento de línguas estrangeiras.

\footnotetext{
${ }^{3}$ A linguagem figurada relaciona níveis de experiência antes distintos, dando novo entendimento a sensações familiares e abertura a novas dimensões perceptivas de um modo que pode ser estimulante, mas também inesperado e até inquietante.
} 
Muitas escolas e muitos profissionais de educação ainda não estão, entretanto, preparados para atuar nesse novo cenário e enfrentar os obstáculos desses significados construídos pelos alunos, é preciso, em primeiro lugar, compreender teoricamente a natureza do letramento como um diálogo entre o indivíduo e a sociedade a partir de suas práticas sociais. Discutindo a questão do texto literário em sala de aula, Ana Paula Rola (2006) lembra que Bakhtin (2004) percebe a linguagem como uma construção social negociada pelos participantes discursivos, que a utilizam para agirem em determinadas situações sociais, culturais e históricas. Da mesma forma, Moita Lopes (2002) aponta a função sociointeracional da linguagem e chama a atenção para o fato de que, se por um lado o significado dos signos é constituído pelos participantes do discurso na própria interação, por outro lado, essa interação permite construir uma imagem de si mesmo e do outro com quem interagimos.

Nessa perspectiva, o ensino de língua estrangeira visa não só o aprendizado de uma linguagem (sua estrutura e seu vocabulário), mas visa uma reflexão sobre uma cultura e uma construção da própria identidade como sujeito participante de uma comunidade global.

Assim, a sala de aula de língua estrangeira pode e deve ser um lugar onde os indivíduos lidem com processos sociais de criação de significados através da língua alvo. Interagindo entre si (comunicativamente) e com a cultura dessa língua através de textos das mais diversas linguagens. Para tanto, os professores precisam pensar estratégias estimulantes que visem a elaboração de interpretações colaborativas sobre textos, em suas conversas ou em suas próprias produções textuais. Assim como atividades que se voltem para a reflexão, a partir do texto literário, sobre si e sobre o mundo. Isso demonstra a importância do professor em sala de aula para a construção da percepção dos alunos como parte de uma sociedade, de uma cultura, de um tempo histórico.

Diante de tudo isso, é fundamental que o material didático elaborado para o ensino de uma língua estrangeira, contemple vários aspectos de sua cultura, não só através do uso das mais diversas tecnologias da informação e da comunicação, mas através de textos que propiciem uma reflexão de qualidade, estimulem a imaginação e a criatividade, caso da literatura.

Pensar a literatura na sala de aula de Espanhol como Língua Estrangeira é pensar não só na formação crítica do aluno, mas na sua inserção na cultura letrada da língua alvo.

\section{CONSIDERAÇÕES FINAIS}

A construção de materiais didáticos que atendam as novas exigências globais em prol da inclusão atiça o clamor por elementos que sirvam de elo de aproximação entre as mais distintas culturas. No caso particular do Brasil, o que se presencia é o paulatino comprometimento com uma educação abrangente e de qualidade.

Vale ressaltar que a viabilidade dos direcionamentos traçados pelo Ministério da Educação, no que concerne o ensino do espanhol como língua estrangeira, depende do efetivo investimento financeiro e sobretudo intelectual para o seu desenvolvimento, merecendo especial atenção a necessidade da oferta de uma infra-estrutura condizente com o que se estabelece nas Leis de Diretrizes e Bases da Educação Nacional, da formação inicial e 
contínua de professores e da elaboração de materiais adequados à realidade que se apresenta.

O texto literário se alia aos novos anseios sociais de construção de uma sociedade justa, consciente de seu poder e conectada com o mundo por proporcionar ao aluno a capacidade de reconhecer as semelhanças e diferenças entre suas idéias, valores e conceitos e os da cultura da língua estrangeira aprendida através de um entendimento intercultural. $\mathrm{O}$ conhecimento de línguas estrangeiras é hoje um elemento crucial para a inclusão do indivíduo unindo-o à sociedade global.

\section{REFERÊNCIAS}

ALBALADEJO GARCÍA, María Dolores. Cómo llevar la literatura al aula de ELE: de la teoría a la práctica. MarcoELE: Revista de didáctica, $\mathrm{N}^{\circ}$. 5, 2007. Disponível em: <http://www.marcoele.com/num/5/02e3c099fc0b38904/albaladejo.pdf >. Acesso em: 12 ago. 2009.

BAKHTIN, Mikhail. Marxismo e filosofia de linguagem. Trad. Michel Lahud e Yara Frateschi Vieira. São Paulo: Hucitec, 2004.

BOGDAN, Robert e BIKLEN, Sari. Investigação qualitativa em educação. Portugal: Porto Editora,1994.

BRASIL. Lei $\mathrm{n}^{0}$ 11.161, de 5 de agosto de 2005. Dispõe sobre o ensino da língua espanhola. Diário Oficial [da] República Federativa do Brasil, Brasília, DF, 8 ago. 2009. Disponível em: <http://www.planalto.gov.br/ccivil_03/_Ato20042006/2005/Lei/L11161.htm>. Acesso em: 08 ago. 2009.

Ministério da Educação e Cultura. Secretaria de Educação Média e Tecnológica. Conhecimentos de Língua Estrangeira Moderna. In:

Nacionais: Ensino Médio. Brasília, 2000. Disponível em: <http://portal.mec.gov.br/seb/arquivos/pdf/14_24.pdf>. Acesso em: 19 maio 2009.

Secretaria de Educação Básica. Orientações curriculares para o ensino médio: linguagens, códigos e suas tecnologias. Brasília: Ministério da Educação, Secretaria de Educação Básica, 2006. 1 CD-ROM

COLLIE, Joanne; SLATER, Stephen. Literature in the language classroom: a resource book of ideas and activities. Cambridge: Cambridge University press, 1987.

DOCUMENTO SÍNTESE do II Encontro Nacional sobre Política de Ensino de Línguas Estrangeiras “Carta de Pelotas". II ENPLE - ENCONTRO NACIONAL SOBRE POLÍTICA DE ENSINO DE LÍNGUAS ESTRANGEIRAS, Pelotas, Universidade Católica de Pelotas, RG, Brasil, 2000.

JUNGER, Cristina Vergnano. El reto del trabajo con compresión lectora en E/LE para profesores y estudiantes brasileños. FIAPE, I Congreso Internacional: el español, lengua del futuro, Toledo, abr. $2005 . \quad$ Disponível em: $<$ http://www.mepsyd.es/redele/biblioteca2005/fiape/vergnano.pdf $>$. Acesso em: 9 ago. 2009. 
LASARO, Flávia Aparecida et al. O Ensino da Literatura em Aulas de Língua Inglesa: Desafio e Vantagens. Disponível em: $<$ http://www.unimep.br/phpg/mostraacademica/anais/4mostra/pdfs/364.pdf>. Acesso em: 09 ago. 2009.

LOPES-ROSSI, M. A. G. Gêneros discursivos no ensino de leitura e produção de textos. In: KARWOSKI, Acir Mário; GAYDECZKA, Beatriz e BRITO, Karim Siebeneicher (Org.). Gêneros textuais reflexões e ensino. $2^{\circ}$ ed. Rio de Janeiro: Lucerna, 2006.

MARTÍNEZ SALLÉS, Matilde. Libro, déjame libre: Acercarse a la literatura con todos los sentidos. RedELE: Revista Electrónica de Didáctica ELE, nº. 0, 2004. Disponível em: <http://www.educacion.es/redele/revista/martinez.shtml>. Acesso em: 12 ago. 2009.

MOITA LOPES, L. P. Identidades Fragmentadas: a construção discursiva de raça, gênero e sexualidade em sala de aula.Campinas: Mercado de Letras, 2002.

ROLA, Ana Paula Carneiro. O uso da leitura em aulas de Espanhol como Língua Estrangeira. In: Linguagem \& Ensino, v.9, n.2, p.57-77, jul./dez. 2006. Disponível em: <http://rle.ucpel.tche.br/php/edicoes/v9n2/03Rola.pdf>. Acesso: 20 de julho de 2009.

SANZ GONZÁLEZ, Félix. La literatura en la clase de lengua extranjera: ¿una presencia incómoda? Didáctica, Madrid, 7, 119-132, Servicio de Publicaciones 11CM, 1995. Disponível em: <http://revistas.ucm.es/edu/11300531/articulos/DIDA9595110119A.PDF>. Acesso em: 09 ago. 2009. 